\section{TRABALHO COLABORATIVO ENTRE PROFESSORES FORMADORES: O QUE REVELAM AS VOZES DO TERRENO?}

\section{COLLABORATIVE WORK AMONG TRAINING TEACHERS: WHAT DO THE VOICES OF THE PRACTICE CONTEXT REVEAL?}

Jamily Vasconcelos Caribé Souza ${ }^{1}$

\section{Introdução}

Tanto a literatura quanto a nossa própria experiência enquanto professores revelam que, no contexto da docência, atualmente, vivemos um importante momento de inúmeras mudanças que colocam em relevo as instituições educadoras, enquanto espaços encarregados de promover aos docentes uma atitude questionadora e reflexiva sobre a sua prática de ensino com vista a melhorar a qualidade daquilo que oferecem aos seus alunos. A colaboração é considerada uma prática emergente, no contexto educacional, e tem sido apresentada como acesso a inúmeros contributos para o fomento do desenvolvimento profissional dos professores (Alarcão e Canha, 2013; Day, 2001; Fullan e Hargreaves, 2001; Hargreaves, 1998; Lima, 2002; Mesquita, Formosinho e Machado, 2015).

\begin{abstract}
RESUMO
Neste estudo, objetiva-se identificar os contributos que o trabalho colaborativo poderá oferecer ao desenvolvimento profissional dos professores formadores (universidade e escola), no estágio supervisionado. Os dados foram coletados a partir de entrevistas semiestruturadas a seis professoras; três professoras de estágio de um curso de licenciatura em uma universidade pública; e três professoras de escolas da educação básica que orientam professores estagiários no âmbito desta disciplina. Analisamos os dados através da técnica da análise de conteúdo. Os resultados evidenciam que a colaboração entre os formadores é desejável. Em contrapartida, os dados também revelaram dificuldades enfrentadas para o estabelecimento de um trabalho em parceria entre esses formadores. Tencionamos, com este estudo, promover uma reflexão mais alargada acerca do que revelam as vozes desses professores, quanto ao papel da colaboração para uma possível renovação de suas práticas de formação.
\end{abstract}

Palavras Chave: Formação Docente. Estágio Pedagógico. Trabalho Colaborativo. Parceria universidade-escola. Desenvolvimento Profissional.

\section{ABSTRACT}

In this study, the main objective is to identify the contributions that the collaborative work can offer to the professional development of the teacher trainers (university and schools), in the experience of the supervised intership, looking for an approximation of these both institutions (university and school). The data were collected, from semistructured interviews, to six teachers; three teachers of supervised curricular internship (supervising teachers) within an undergraduate course at a public university; and three school teachers (cooperating teachers) who tutor trainees under this discipline. We analyze the data through the technique of content analysis. The results show that the collaboration among the training teachers during the internship activities is desirable. On the other hand, the data also revealed difficulties faced by these supervising and cooperating teachers for the establishment of a work in partnership between these training teachers. With this study, we intend to promote a broader reflection on what the voices of these teachers reveal, and the role of collaborative work for the empowerment of these training teachers and for a possible renewal of their pedagogical practices.

Keywords: Teacher training. Supervised internship. Collaborative work. University-school partnership. Professional development.

Submetido em: 04 de abr. 2019

Aceito em: 17 de dez. 2019

${ }^{1}$ Universidade do Estado da Bahia, Santo Antonio de Jesus, Bahia - Brasil

E-mail para correspondência: jamilycaribe@gmail.com

Rev. ComCiência - dez. 2019, vol. 4, no. 5, p. 13-27/ doi: 10.36112/issn2595-1890.v5i2.p13-27 
A partir deste contexto, o presente estudo ${ }^{2}$ apresenta como proposta a construção de um trabalho de colaboração entre os professores formadores, tanto da universidade quanto da escola, no âmbito da disciplina estágio curricular supervisionado, na formação inicial de professores, para que se possa perspectivar a formação de futuros professores alinhada às reais demandas da sala de aula.

Para tanto, analisaremos, inicialmente, os seguintes temas: o estágio supervisionado como espaço de encontro entre universidade e escola, trabalho colaborativo: potencia-lidades e constrangimentos. A partir desse aporte teórico, teremos a compreensão de como a experiência do estágio supervisionado, com a presença de um trabalho colaborati-vo, poderá gerar saberes que estruturem o desenvolvimento profissional dos sujeitos envolvidos, minimizando as difi-culdades existentes nessa relação universidade-escola, na construção do conhecimento profissional.

Assim, tivemos acesso às vozes dos professores formadores, a partir de entrevistas, para identificarmos os contributos que o trabalho colaborativo poderá oferecer ao desenvolvimento profissional desses sujeitos, na experiência de estágio supervisionado.

Os resultados obtidos poderão contribuir para a afirmação de uma cultura de colaboração entre os professores formadores e motivar mais investigadores a desenvolver estudos que contemplem essa partilha de experiências e saberes interpares, construindo, assim, uma nova dinâmica de trabalho e organização pedagógica, nas institui-

${ }^{2}$ Este artigo decorre de uma pesquisa de doutorado em educação, no ramo da Didática e Desenvolvimento Curricular que incide sobre o contexto de formação inicial de professores, no âmbito da unidade curricular Estágio Supervisionado. ções de formação universidade e escola.

\section{Estágio Supervisionado como Espaço de Encontro entre Universidade e Escola}

Falar em formação nunca dispensa a presença e a importância conferida ao estágio curricular supervisionado, para uma melhor compreensão da construção da prática docente. Acreditamos que um dos objetivos da formação docente é possibilitar ao professor em formação a percepção e análise das situações de ensino. Assim, é vivenciando a experiência do estágio que o professorestagiário poderá ter a oportunidade de desenvolver uma percepção do funcionamento e das especificidades da sua profissão, em um contexto real de ensino e aprendizagem.

Nessa direção, Araújo e Sá (1999) defende que a função precípua do estágio pedagógico é preparar o aluno-futuro-professor para lidar com as ações educativas complexas e múltiplas que lhe são exigidas pelo sistema escolar, proporcionando-lhe o desenvolvimento da sua capacidade de compreensão dos contextos, através da observação crítica, da experimentação e da ação. A autora complementa que é a partir da vivência do estágio pedagógico que o professor estagiário compreenderá a organização e funcionamento dos contextos educativos Universidade, Escola, Secretarias de Educação, Sistemas de Ensino, e experimentará a teoria na prática da sala de aula, colocando os seus saberes docentes em ação e construindo outros a partir dessa experiência.

Essa perspectiva deixa claro que o estágio pedagógico: tem como objetivo proporcionar ao professor em formação a oportunidade de aplicar seus conhecimentos acadêmicos em situações da prática profissional clássica, criando a possibilidade do exercício de suas habilidades. Espera-se que, com isso, o professor estagiário tenha a opção de incorporar atitudes práticas e adquirir uma visão crítica de sua área de atuação rofissional (OLIVEIRA E CUNHA,2014, p.7).

Dessa citação depreende-se que, a experiência do estágio curricular supervisionado deverá possibilitar ao professor estagiário esse olhar reflexivo e crítico da atividade docente com vista a reinventar novas formas ou construir maneiras muito particulares de atuar na sua prática de ensino. Nesse sentido, é fundamental compreendermos que "o estagiário para construir o seu presente e o seu futuro, tem de ser capaz de interpretar o que assiste fazer, de imitar sem realizar cópias, de recriar, de transformar" (ALARCÃO, 1996, p. 33).

Compartilhando com o pensamento da referida autora, Pimenta (1999) defende que o professor estagiário, nesse exercício de conhecer diretamente, a partir da experiência de estágio, as realidades escolares e os sistemas onde o ensino ocorre, com olhos não mais de alunos, mas de futuros professores, em um contexto de vivência da prática docente, é um passo significativo na tentativa de construir a profissão docente.

Neste sentido, é necessário pontuarmos que os professores em formação, vivenciando a prática de estágio encontram possibilidades de estabelecer um diálogo dos saberes apreendidos na formação com os saberes existentes no terreno, ou seja, nas situações de trabalho. Sob essa perspectiva, Dubar (2003, p.49) 
assinala que, na formação inicial, os professores formadores devem trabalhar com os futuros professores aconcepção de formação para o trabalho da docência que segundo o referido autor deve "desenvolver os saberes práticos, úteis para o trabalho e adquiridos diretamente pelo seu exercício. Para que serve ter conhecimentos se estes não servirem para mudar as condições ou os resultados do trabalho?"

Nessa direção, Felício e Oliveira (2008) consideram o estágio pedagógico um momento propício para a articulação da situação de formação com a situação de trabalho. Compreendemos, assim, que essa articulação entre esses dois momentos específicos, oferece uma significativa contribuição para a formação prática dos futuros professores.

Baseados na importância conferida à prática, nesse momento do estágio supervisionado, pensamos ser necessário compreendermos a concepção de prática pedagógica. Para Lima (2001, p. 47), "a prática sempre esteve presente na formação do professor" e, no que tange a experiência do estágio pedagógico, essa prática é construída a partir da observação de modelos considerados como "bons", com vista a aprender a profissão. É assim que iniciamos a nossa percepção do que é ensinar. Primeiro observa-se, segundo imita-se para, posteriormente, construir-se a sua própria forma de ensinar. Nesse processo, os professores aprendizes "escolhem, separam aquilo que consideram adequado, acrescentam novos modos, (...) para isso, lançam mão de suas experiências, e dos saberes que adquiriram" (LIMA; PIMENTA, 2009, p. 35).

$\mathrm{Na}$ direção da compreensão de prática pedagógica, Gómez e Pérez
(2001) a interpretam como uma rede de troca de experiências, criação e transformação de significados. Com efeito, o sentido de prática, sob essa perspectiva, vai além da mera aplicação e experimentação de modelos observados. É uma atividade que possibilita a intervenção e possível transformação de um contexto educativo. Com efeito, Prática precisa ser entendida, como Práxis, ou melhor, necessita ser uma atitude teóricoprática, humana, transformadora da realidade. Entender a prática enquanto práxis é constatar a indissolubilidade entre a teoria e a prática (LIMA, 2001).

Se a vivência da prática se faz presente, no momento em que os professores aprendizes adentram a sala de aula, para experienciarem o estágio pedagógico, as universidades e as Escolas, que são agências formadoras, precisam estar em permanente diálogo para que a prática docente construída, a partir dessa experiência de estágio, seja práxis, e como tal promotora de transformações. Por isso, é fundamental aproximarmos esses dois contextos formativos com vista à "construção de uma relação estratégica entre a formação e o trabalho, em que o essencial consiste na capacidade de desenvolver um reflexo de aprendizagem permanente que permita aprender a identificar o que é necessário saber e a aprender a aprender com a experiência" (Canário, 2001, p.35).

Assim, a discussão sobre o papel do estágio pedagógico na formação docente está conectada a um processo dialógico, que precisa ser constante, entre a universidade ea escola. Esse diálogo possibilitará uma relação mais próxima entre os professores dos dois contextos, diminuindo assim a divergência entre a teoria didática de formação docente construída e difundida pela universidade, e a prática docente vivenciada pelos professores estagiários nas escolas campo. Com efeito, os saberes da teoria estarão em consonância com os saberes da prática, a partir de um trabalho colaborativo entre esses professores formadores.

Seguindo essa linha de raciocínio, se faz necessário pontuar que, o estágio pedagógico, por ser um contexto de encontro entre universidade e escola, precisa ser compreendido como um momento que viabiliza a formação horizontal dos professores formadores, ou seja, formação esta em que diferentes saberes (da prática e da investigação) possam se encontrar e interagir, de modo que sejam reconstruídos. Em nosso entender, esse encontro poderá também permitir que os papéis de formação sejam repensados. Neste sentido, Vieira (2009, p. 271, tradução nossa.) defende que:

\begin{abstract}
A colaboração entre pesquisadores e professores tem como objetivo construir metas comuns, enfraquecendo as barreiras entre a pesquisa e o ensino e colocando as duas comunidades docentes em confronto com o mesmo objeto de estudo - a educação - apesar das diferentes formas de olhar esse objeto e de agir sobre ele ${ }^{3}$.
\end{abstract}

A partir da perspectiva da referida autora, a colaboração poderá minimizar, ou melhor, desconstruir essa linha divisória que existe entre os investigadores (professores da universidade) e os professores da escola.

${ }^{3}$ collaboration between researchers and teachers in persuing common goals is a way of weakening the barriers between research and teaching and bringing together two communities that confront the same object of study - education - although with different ways of looking and acting 


\section{Trabalho Colaborativo: potencialidades e constrangimentos}

A evolução acelerada da sociedade devido à informação tecnológica cada vez mais presente no nosso cotidiano, demanda uma formação de professores mais condizente aos desafios emergentes do contexto educacional contemporâneo. No que respeita a importância do estágio para a formação docente, é fácil compreendermos que essa experiência representa um dos elementos estruturantes para a constituição da prática docente de qualidade. Com base nessas considerações, pensamos que se torna cada vez mais imperativo que a universidade repense e revise este componente curricular, resignificandoo, a partir das exigências atuais do contexto de ensino e aprendizagem da educação básica. Nessa direção, Imberón defende que:

As instituições formadoras devem superar definitivamente os enfoques tecnológicos, funcionalistas e burocratizantes, aproximando-se, ao contrário, de seu caráter mais relacional, mais dialógico, mais culturalcontextual, (...) em cujo âmbito adquire importância a relação que se estabelece entre todas as pessoas que trabalham dentro e fora dela. (IMBERÓN, 2011, p. 8)

Para bem perspectivar essa formação defendida pelo referido autor, parece-nos importante pensarmos a formação docente sob a perspectiva do Trabalho Colaborativo (TC). Entendemos por TC uma prática que apresenta grandes potencialidades, já que:

nasce da interação entre pessoas, da partilha de conhecimento e de saber experiencial, da equidade na assunção de responsabilidades sobre os percursos de ação, proporcionando nesse processo a reconstrução do conhecimento e, espera-se, a mudança das práticas e o desenvolvimento. (ALARCÃO; CANHA, 2013, p. 51).

Os referidos autores, na definição de TC acima, utilizam-se de cinco palavras que, em nossa opinião, promovem a mudança esperada e necessária no contexto de formação e no processo de ensino e aprendizagem desses futuros professores. Interação, partilha, equidade, reconstrução e desenvolvimento são palavras de fundamental importância para a construção desta cultura da colaboração. A nosso ver, das palavras que foram mencionadas, na definição sobre TC por Alarcão e Canha (2013), a palavra interação é a que apresenta uma significativa importância para o TC, compreendido neste estudo, embora as outras palavras também ocupem o seu lugar de importância.

É a partir da interação entre professores formadores, através do TC, que experiências e saberes poderão ser partilhados, possibilitando, assim, uma aproximação dos universos formativos Escola e Universidade. Importa também questionarmos: quais as benesses que o TC proporciona? Quais as suas mais-valias? O TC poderá fazer uma real diferença na prática dos professores formadores e no aprendizado dos professores estagiários? Rodrigues, Nolasco e Fiadeiro (2010, p. 30) salientam que:

O processo de colaboração é importante entre colegas, entre escolas e entre instituições de diferentes níveis de ensino. A colaboração é benéfica na medida em que aumenta o sentido de eficácia dos professores, e das instituições e reduz o sentimento de impotência, pois não contempla a natureza fragmentada e isolada da aprendizagem, privilegia a interação, os contextos, a flexibilidade e a mudança de práticas.

A contribuição das autoras sobre as mais-valias do TC ajuda-nos a compreender a sua importância para o desenvolvimento organizacional das instituições e o desenvolvimento profissional dos seus membros. Segundo Damiani (2008), na colaboração, ao trabalharem juntos, os participantes de um grupo se apoiam, com o intuito de atingir objetivos comuns negociados pelo coletivo, estabelecendo relações que tendem a não-hierarquização, liderança compartilhada, confiança mútua e coresponsabilidade pela condução das ações. A cultura da colaboração "é uma atitude, um modo de estar, um compromisso que precisa de ser cultivado, acarinhado, incentivado, apreciado" (ALARCÃO, 2010, p. 8).

Assim, acreditamos que para haver o desenvolvimento dessa cultura colaborativa, em um contexto formativo, os professores devem estar com o espírito aberto para vivenciar essa experiência em seu quotidiano, pois percebemos que essa cultura nasce dessa disponibilidade ao partilhar, ao se relacionar com os outros, ao construir junto para se alcançar um objetivo comum, que, no caso específico deste estudo, é a formação docente, apartir da unidade curricular estágio pedagógico que contemple as exigências dessa experiência formativa.

Cabe ainda dentro dessa temática, chamarmos a atenção para a compreensão dos significados da colaboração e da colegialidade artificial que são, frequentemente, debatidas como se fossem sinônimas. Deste modo, Hargreaves ( 2001, p. 212-213) pontua que "na nossa pressa 
abrupta para gerir a colaboração e a colegialidade, parece ser importante, portanto, que encontremos, em primeiro lugar, tempo para compreender o seu significado". Relativamente a colegialidade artificial ela é regulada administrativamente. É compulsiva, pois faz com que o trabalho em conjunto se torne uma obrigação. Se verifica também que as situações de colegialidade artificial são orientadas para a implementação, ou seja, os docentes são obrigados ou "persuadidos" a trabalhar em conjunto, tendo em vista implementar ordens de outros mais diretamente, as do diretor de escola, por exemplo. São fixas no tempo e no espaço. E, por fím, são previsíveis, pois são situações concebidas para produzir resultados que se caracterizam por um grau de previsibilidade relativamente elevado. Ademais, o controlo de suas finalidades e a regulação do tempo e lugar da sua concretização são pensadas para aumentar tal previsibilidade (Hargreaves, 2001).

Ainda, segundo o mesmo autor, nas culturas de colaboração autêntica, as relações estabelecidas entre os professores apresentam as seguintes características: contrariamente às relações de colegialidade, as relações sob o cariz colaborativo são espontâneas, pois partem dos próprios professores, enquanto grupo social. Entretanto, essa espontaneidade não é absoluta, pois essas relações colaborativas podem ser apoiadas e facilitadas administrativamente por calendarizações úteis, por diretores de escolas, por exemplo. São voluntárias, pois resultam da percepção que os docentes têm do seu valor - trabalhar em conjunto é agradável e produtivo.

As ações dos professores envolvidos nessa cultura de colaboração autêntica estão orientadas para o desenvolvimento. Os professores trabalham em conjunto, principalmente, para desenvolver seus próprios projetos, nos quais eles próprios estão empenhados. Essas atividades são difundidas no tempo e no espaço. Os encontros são informais, breves, mas frequentes. Ademais, são regulados a partir da própria forma como a vida profissional dos professores se desenrola na escola. Conclui-se, finalmente, que a imprevisibilidade é uma forte característica desta cultura. Os resultados da colaboração autêntica são, de modo geral, incertos e dificilmente previsíveis.

Após termos uma melhor compreensão sobre os conceitos de colegialidade artificial e colaboração autêntica, faz-se necessário pontuarmos que as relações colaborativas não são fáceis de serem construídas. Há muito tempo a docência tem sido designada por "a profissão solitária” (Fullan e Hargreaves, 2001; Lortie, 1975), e sabemos que muitos são os constrangimentos enfrentados pelos professores para estarem juntos a trabalhar. Este isolamento físico é revelado pelas salas de aula segregadas de muitas de nossas escolas - são as "eggcrateschool" - estrutura de escola em caixa de ovos, termo cunhado por Lortie (1975) em seu estudo sobre a cultura do isolamento dos professores.

Outro ponto que se faz necessário ressaltar é que há muita expectativa em torno de os professores cultivarem essa cultura de trabalho colaborativo, mas, em contrapartida, se faz necessário questionarmos: os docentes encontram um ambiente propício, em seus contextos de trabalho, para o desenvolvimento dessa cultura? Tem sido argumentado por Roldão (2007) que não podemos esperar que os professores trabalhem colaborativamente, sem que as instituições estejam dispostas a mudar também as suas regras organizacionais e contextuais, abrindo espaço ao trabalho entre docentes, sob essa perspectiva.

Para além destas referidas questões organizacionais das instituições de ensino que promovem esse isolamento entre os professores, Fullan e Hargreaves (2001) pontuam que duas das principais causas do individualismo não são de natureza material: elas baseiam-se nas normas e nas condições tradicionais de ensino. A primeira delas está diretamente ligada as experiências de avaliação vividas pelos professores em diferentes momentos formativos. Ainda Fullan e Hargreaves (2001, p.77) salientam que:

\begin{abstract}
$\mathrm{Na}$ maioria dos casos, as suas primeiras experiências de terem outros adultos na sua sala de aula ocorreram em situações em que foram avaliados quando se sentiam muito vulneráveis na aprendizagem do seu ofício. (...) Estes momentos iniciais do ensino não deixam de ser um período formativo em que a ajuda é confundida e, por vezes, obscurecida pelo julgamento.
\end{abstract}

Em nosso entender, a partir do exposto, compreendemos que trabalhar sob a égide do isolamento e do individualismo, por mais contraditório que possa parecer, podegerar um sentimento de conforto para o professor, pois este, a princípio, está livre de julgamentos, críticas e cobranças dos seus pares.Partindo desse pressuposto, Fullan e Hargreaves(2001, p. 77) reforçam que "o isolamento e o individualismo são a sua armadura, a sua proteção contra o escrutínio e a intrusão". 
Uma segunda causa que contribui para enraizar a cultura do individualismo e isolamento entre os professores está assente na alta expectativa que eles têm de si próprios. Sabemos que a docência é uma tarefa que demanda uma multiplicidade de competências, para além da competência central que é a de desenvolver um ensino que contemple a aprendizagem dos alunos. Nesta direção, Fullan e Hargreaves (2001, p. 78-79) pontuam:

\begin{abstract}
Nos últimos anos, os professores do ensino elementar têm sido confrontados com uma série de pressões crescentes, e de expectativas mais exigentes relativamente à excelência, num leque de responsabilidades cada vez mais alargado; (...) integrar os alunos da educação especial, trabalhar com alunos étnica e linguisticamente diversos, individualizar os planos de estudos dos alunos, assegurar toda a preparação e preenchimento de papelada (...) tudo isto são pressões com as quais os docentes têm sido confrontados nos últimos tempos.
\end{abstract}

As pressões e expectativas pontuadas podem ser consideradas externas, oriundas de demandas administrativas e organizacionais de um contexto de ensino. No entanto, muitas das pressões e expectativas, advêm, também, dos próprios professores. Muitos destes já se pressionam a si próprios, suficientemente bem, e não parecem precisar de orientações e pressões vindas de fora para persistirem nesta busca de realizarem um trabalho de perfeição

(HARGREAVES,2001). Nesse sentido, é de se destacar que as referidas pressões e altas expectativas que os professores nutrem acerca das suas práticas podem maximizar, ainda mais, a cultura individualista de trabalho e gerar duas consequências que: a falta de tempo por parte dos professores para colaborar; e o entendimento de que a colaboração é uma atividade arriscada (HARGREAVES,2001, p.80).

No que tange a primeira consequência, "uma vez que há tanta coisa para ser feita, o tempo da colaboração é retirado ao que é necessário para satisfazer as necessidades urgentes da própria turma". Assim, os professores preferem estar envolvidos com as muitas tarefas que já fazem parte de sua rotina de trabalho, a dedicarem-se à colaboração.

No que respeita a segunda consequência, Cosme e Trindade (2002) ressaltam que o medo do julgamento dos colegas, da exposição do seu trabalho aos olhos dos outros, confessar publicamente que nem sempre se consegue lidar com muitos imprevistos inerentes a prática de ensino que surgem, diariamente, podem gerar um sentimento de incerteza e incompetência, reforçando assim o risco em se trabalhar colaborativamente.

A partir do exposto, ressaltamos que não é fácil deixarmos uma cultura de trabalho individualista, arraigada há muito tempo no nosso habitus profissional para vivenciarmos com os nossos pares essa nova perspectiva de trabalho que implica a exposição das nossas inseguranças, fragilidades, dúvidas que, eventualmente, permeiam a nossa prática. Nesta ótica, Lima (2002, p.10) assinala que "apesar daquilo que os docentes podem obter, os professores também sentem que podem perder ao colaborarem com os colegas, na medida em que as suas práticas e competências ficam expostas aos olhares críticos de seus pares". Assim, para além das mais-valias que o trabalho colaborativo oferece aos professores, constatamos que inúmeras são as dificuldades para a sua implementação e muitos são os constrangimentos a que os professores estão submetidos.

O que pode ser feito, então, para que o TC possa ser uma realidade? Lima (2002) aponta, em seu estudo sobre as culturas colaborativas nas escolas, que o isolamento profissional não pode ser visto como uma fatalidade e que a lógica das culturas de trabalho docente tem carácter localizado e dinâmico, abrindo assim caminho à questão de saber como fazer das escolas espaços que oportunizem a interação colegial, quando os professores se predispuserem a se envolver neste tipo de relacionamento profissional. A este nível, ainda segundo o mesmo autor, as estratégias de intervenção poderiam estar assentes em políticas públicas e projetos colaborativos institucionais, visando a dissolução ou a flexibilização das fronteiras interdepartamentais para fomentar novas oportunidades de interação entre os docentes no interior das instituições educativas.

Relativamente as estratégias para promover e potenciar a colaboração Forte e Flores (2010) defendem a organização de reuniões conjuntas para a partilha; a transformação dos departamentos curriculares em oficinas de trabalho; a disponibilidade de espaços físicos para o desenvolvimento de projetos e atividades e também a leccionação de aulas em conjunto e a observação de aulas por pares. Uma outra estratégia indicada pelas autoras diz respeito "a uma melhor divulgação das atividades quer interna, quer externamente para toda comunidade, permitindo assim uma maior visibilidade e 
reconhecimento do trabalho realizado" (FORTE; FLORES, 2010, p. 95).

Este é, aliás, um aspecto muito importante; a visibilidade $\mathrm{e}$ credibilidade do TC. Quando trabalhamos colaborativamente, tornamos esse trabalho público, porque deixamos de lado, por alguns instantes a nossa própria individualidade $\mathrm{e}$ priorizamos o coletivo, a equipe, o estar com, objetivando a concretização de um empreendimento conjunto que promoverá o desenvolvimento pessoal, profissional dos sujeitos envolvidos e, igualmente, o desenvolvimento organizacional das instituições.

\section{Metodologia do Estudo}

Este estudo fundamenta-se no paradigma fenomenológico e interpretativo, de natureza qualitativa. Assumimos como pergunta norteadora deste artigo: quais os contributos que o trabalho colaborativo pode oferecer, na experiência de estágio, ao desenvolvimento profissional dos professores formadores (professores das universidades e das escolas)? E, no sentido de obtermos respostas para essa questão, trazemos aqui as vozes dos professores formadores, vozes essas analisadas a partir de inquérito por entrevista que, segundo Sousa e Baptista (2011, p. 79):

é um método de recolha de dados que consiste em conversas orais, individuais ou de grupos, com várias pessoas, cuidadosamente selecionadas, cujo grau de pertinência, validade e fiabilidade, é analisado na perspectiva dos objetivos de recolha de informações.

No que toca à estrutura da entrevista, escolheu-se a semiestruturada. Para tal, foi desenhado um guião de entrevista que "é um instrumento onde se define e registra, numa ordem lógica para o entrevistador, o essencial do que se pretende obter, embora, na interação se venha a dar uma grande liberdade de resposta ao entrevistado" (Amado e Ferreira, 2014, p. 208).

O guião foi constituído por seis questões, porém focamos a nossa atenção na questão que contempla o trabalho colaborativo, para fazermos um recorte que nos possibilitasse obter respostas para a questão norteadora deste trabalho. A referida questão apresenta as concepções que os sujeitos entrevistados têm a respeito de contribuições que o TC poderá oferecer ao desenvolvimento profissional dos professores formadores.

Para a realização deste trabalho selecionamos uma amostra intencional dos sujeitos que como afirmam Amado e Ferreira (2014), representa situações que se querem investigar, ou seja, estes sujeitos, pelas suas experiências de vida e de prática docente, estão envolvidas ou em contato muito próximo com o problema que se deseja estudar. No total foram entrevistadas seis professoras formadoras, todas do sexo feminino e faixa etária entre 3055 anos.

A escolha desses sujeitos seguiu o seguinte critério: no tocante aos formadores da universidade - serem professores da disciplina estágio curricular supervisionado e terem ou já terem tido experiência de ensino na educação básica. Quanto aos formadores das escolas - orientarem ou já terem orientado professores estagiários em suas salas, nos últimos cinco anos. O lócus do estudo foram cursos de licenciatura de uma universidade pública do estado da Bahia e escolas de educação básica, estaduais ou municipais, conveniadas à esta universidade. $\mathrm{O}$ quadro abaixo sintetiza o perfil das professoras entrevistadas.

\begin{tabular}{|c|c|c|c|}
\hline $\begin{array}{c}\text { Professor } \\
\text { formador } \\
\text { (universidade } \\
\text { e escola) - } \\
\text { código }\end{array}$ & Idade & $\begin{array}{l}\text { Local de } \\
\text { trabalho }\end{array}$ & $\begin{array}{l}\text { Tempo de } \\
\text { docência }\end{array}$ \\
\hline $\begin{array}{l}\text { Professora } \\
\text { Escola (PE1) }\end{array}$ & 48 & $\begin{array}{l}\text { Colégio } \\
\text { Municipal }\end{array}$ & $\begin{array}{l}22 \text { anos na } \\
\text { educação } \\
\text { básica }\end{array}$ \\
\hline $\begin{array}{l}\text { Professora } \\
\text { Escola (PE2) }\end{array}$ & 37 & $\begin{array}{l}\text { Colégio } \\
\text { Estadual }\end{array}$ & $\begin{array}{l}12 \text { anos na } \\
\text { educação } \\
\text { básica }\end{array}$ \\
\hline $\begin{array}{l}\text { Professora } \\
\text { Escola (PE3) }\end{array}$ & 53 & $\begin{array}{l}\text { Escola } \\
\text { Municipal }\end{array}$ & $\begin{array}{l}20 \text { anos de } \\
\text { educação } \\
\text { básica }\end{array}$ \\
\hline $\begin{array}{l}\text { Professora } \\
\text { Universidade } \\
\text { (PU1) }\end{array}$ & 40 & $\begin{array}{l}\text { Universidade } \\
\text { pública no } \\
\text { estado da } \\
\text { Bahia }\end{array}$ & $\begin{array}{l}06 \text { anos na } \\
\text { educação } \\
\text { básica/ } 09 \\
\text { anos no } \\
\text { ensino } \\
\text { superior }\end{array}$ \\
\hline $\begin{array}{l}\text { Professora } \\
\text { Universidade } \\
\text { (PU2) }\end{array}$ & 35 & $\begin{array}{l}\text { Universidade } \\
\text { pública no } \\
\text { estado da } \\
\text { Bahia }\end{array}$ & $\begin{array}{l}03 \text { anos na } \\
\text { educação } \\
\text { básica/ } 06 \\
\text { anos no } \\
\text { ensino } \\
\text { superior }\end{array}$ \\
\hline $\begin{array}{l}\text { Professora } \\
\text { Universidade } \\
\text { (PU3) }\end{array}$ & 39 & $\begin{array}{l}\text { Universidade } \\
\text { pública no } \\
\text { estado da } \\
\text { Bahia }\end{array}$ & $\begin{array}{l}10 \text { anos na } \\
\text { educação } \\
\text { básica/ } 04 \\
\text { anos no } \\
\text { ensino } \\
\text { superior }\end{array}$ \\
\hline
\end{tabular}

As entrevistas foram áudiogravadas e transcritas e os dados coletados foram analisados através da técnica da análise de conteúdo. SegundoAmado e Ferreira (2014), esta técnica permite, além de uma rigorosa e objetiva representação dos conteúdos, através da sua codificação e classificação por categorias e subcategorias, o avanço fecundo e sistemático com o propósito de captar os contextos ou condições do objeto investigado.

Em seguida, apresentamos as categorias que balizaram essa interpretação, porém, antes de abordálas de uma forma mais detalhada, gostaríamos de ressaltar que foram também levantadas subcategorias, mas as mesmas não serão trabalhadas neste estudo. Assim, foram emergentes dos dados, três categorias, como segue:

a) Os significados do TC 
b) As mais-valias do TC

c) As dificuldades para a implementação do TC

Apresentamos um quadro abaixo com as categorias, descrição, as siglas que as representam, e falas dos professores extraídas das entrevistas para exemplificá-las.

\begin{tabular}{|c|c|c|}
\hline $\begin{array}{c}\text { Categorias } \\
\text { - siglas }\end{array}$ & Descrição & Exemplos \\
\hline $\begin{array}{l}\text { Significados } \\
\text { do TC (SIG) }\end{array}$ & $\begin{array}{l}\text { A percepção que } \\
\text { os sujeitos } \\
\text { entrevistados têm } \\
\text { sobre essa cultura } \\
\text { de trabalho } \\
\text { docente e a } \\
\text { importância que } \\
\text { eles atribuem a } \\
\text { essa prática. }\end{array}$ & $\begin{array}{lr}\text { "Trabalhar } & \text { "na } \\
\text { colaboração } & e ́ \\
\text { trabalhar } & \\
\text { socializando } & \\
\text { práticas, saberes, } & \\
\text { certezas, dúvidas, } & \text { sucessos, } \\
\text { fracassos } & \text { com } \\
\text { espirito de } & \text { apoio } \\
\text { e } & \text { ajuda } \\
\text { constante". } & \text { (PU1, } \\
\text { SIG3) } & \end{array}$ \\
\hline $\begin{array}{l}\text { Mais- } \\
\text { do TC }\end{array}$ & $\begin{array}{l}\text { Essa categoria } \\
\text { nos apresenta as } \\
\text { contribuições que } \\
\text { o TC oferece ou } \\
\text { poderá oferecer à } \\
\text { prática } \\
\text { pedagógica e ao } \\
\text { desenvolvimento } \\
\text { profissional dos } \\
\text { professores } \\
\text { entrevistados. }\end{array}$ & $\begin{array}{l}\text { “... nos faz sentir } \\
\text { mais poderosos, } \\
\text { mais proativos } \\
\text { para tratarmos } \\
\text { dos nossos } \\
\text { problemas, para } \\
\text { realizarmos os } \\
\text { nossos projetos” } \\
\text { (PU1, MV3). }\end{array}$ \\
\hline $\begin{array}{l}\text { Dificuldades } \\
\text { na } \\
\text { implementaç } \\
\text { ão do TC } \\
\text { (DIF) }\end{array}$ & \begin{tabular}{lr}
\multicolumn{2}{l}{ Os obstáculos } \\
existem \\
contexto & no \\
trabalho & de \\
igualmente, no \\
habitus \\
profissional \\
destes professores \\
que dificultam a \\
experiência do \\
trabalho \\
colaboração.
\end{tabular} & \begin{tabular}{|lr} 
"Só que eu \\
percebo que é \\
muito dificil, pois \\
nem rodo \\
professor está \\
dispostor \\
trabalhar assim" \\
(PE3, DIF2).
\end{tabular} \\
\hline
\end{tabular}

\section{Apresentação e discussão dos dados}

Os dados serão apresentados focando, em um primeiro momento, os significados que os professores entrevistados dão ao TC e, num segundo momento, as suas mais-valias e as dificuldades encontradas para os professores formadoresimplementarem e experienciarem essa cultura da colaboração em suas práticas.

Para uma melhor compreensão dos dados apresentados, a seguir utilizaremos as siglas (PU) para identificar os professores formadores da universidade e (PE) para os professores formadores das escolas, já apresentadas no quadro acima.

\section{a) Significados de TC na visão dos professores entrevistados}

Os professores formadores entrevistados atribuem significados positivos quanto a cultura de trabalho colaborativo. Vejamos o que suas falas revelam:

"Sujeitos com diferentes experiências. Um ouvindo o outro, uns dividindo com os outros conhecimentos, sucessos, aprendizados, dilemas, um dando suporte ao outro, muitas trocas". (PE1, SIG1)

"aqui na escola os professores até trabalham na colaboração: eles planejam juntos, fazem os testes/provas coletivamente, discutem problemas sobre os alunos, pedem sugestões/conselhos a outros colegas". (PE2, SIG4)

No que respeita aos significados atribuídos ao TC, as falas dos professores acima foram unânimes ao revelarem que trabalhar sob a égide da colaboração traz benefícios para eles lidarem com as tarefas inerentes a sua prática profissional. Nessa direção, a presença das palavras escuta, partilha, suporte, troca, socialização, nas referidas falas, expressam bem a compreensão que os mesmos têm do que é trabalhar em colaboração e a necessidade de esse espírito de suporte e entreajuda estarem presentes nas suas rotinas de trabalho.

Nessa perspectiva, Alarcão (2010) defende que em contextos de formação colaborativa, se faz necessário o "estar com” que a autora associa com apoio e coesão. Para além disso, há uma grande necessidade de suporte, de estar junto, de ajudar, de ser ajudado, em um desejo de "juntos fazemos melhor", envolto em uma crença de resultados significativos para o desenvolvimento profissional de todos os sujeitos envolvidos nesse processo.

Percebe-se, na fala de outra professora formadora, que o TC representa um elemento necessário para estreitar a relação universidade e escola.Prestemos atenção a narrativa a seguir.

“a partir do trabalho
colaborativo nós somamos
experiências. As experiências
de um professor formador (da
universidade), do professor
regente (da escola) que
compartilham o seu saber, a sua
experiência com esse professor
que está em formação
(oestagiário) .... Eu penso que
essa experiência que todos
trazem, que compartilham uns
com os outros, é uma
experiência bem diferente da
experiência que temos, a partir
da teoria que dominamos que,
muitas vezes, é uma teoria que
não é construída para nossa sala
de aula, mas uma teoria fictícia
.. muito longe do real". (PU2,
SIG7)

Depreendemos da narrativa acima que, a partir das trocas de saberes e experiências, advindos da interação que se estabelece entre os professores formadores, a formação desenvolvida na universidade, encontra-se melhor relacionada com as demandas da sala de aula real. Deste modo, a formação desse aluno que irá vivenciar a experiência do estágio pedagógico, estará mais alinhada a uma perspectiva mais prática de formação, diminuindo assim o distanciamento existente entre a teoria ensinada e difundida na universidade e a prática vivenciada na experiência de estágio. Nessa direção, Lago, Oliveira e Adelino(2012) põem em relevo a 
necessidade de o TC ser uma realidade nos cursos de formação de professores, pois os participantes envolvidos nessa dinâmica internalizam normas, hábitos, habilidades e entendimentos, que se caracterizam como um conjunto de saberes importantes para apreender a realidade partilhada entre a universidade e a escola.

Também foi enfatizado por uma das professoras que o TC entre os professores formadores, tanto da universidade quanto da escola, é desejável. Assim, a referida professora ressalta a necessidade de haver um projeto com metas estabelecidas para serem alcançadas, através do trabalho colaborativo. Essa parceria entre os professores dos dois contextos formativos poderá promover possíveis melhorias nas ações docentes e institucional e, consequentemente, mudanças educativas que reflitam na aprendizagem dos alunos, no caso específico deste estudo, os professores estagiários. Com efeito, o excerto abaixo exemplifica bem essa questão. "corpo docente da universidade juntamente com corpo docente da escola para preparar bem o estagiário para a vivência do estágio".(PU1, SIG3)

Essa seria a forma ideal de trabalho em colaboração, a partir dessa relação dialógica entre os professores formadores dos dois contextos: universidade e escola. Este pensamento é corroborado por Pinto e Leite (2014) que associam o conceito de TC "aos conceitos de autonomia profissional e institucional e pressupõe que com ele sejam geradas condições de melhoria de práticas profissionais, curriculares e organizacionais, em consequência de ações potencializadas pelo esforço coletivo em prol de objetivos comuns" (2014, p.150).

Não podemos deixar de pontuar que as falas dos inquiridos revelam que, trabalhar em colaboração, não deveria se resumir a um trabalho conjunto pontual entre professores formadores no cumprimento da unidade curricular estágio pedagógico. Vejamos a fala abaixo:

\begin{abstract}
"Por outro lado, não vejo esses professores da escola e os da universidade trabalharem juntos. Só no momento do estágio, que é um momento pontual (...) eu penso que trabalhar na colaboração não seja assim. Tem que haver mais diálogo, mais troca, mais participação no processo como um todo. Tem que haver um início, meio e fim (...) por exemplo, um projeto de formação dos estagiários, de acordo com as necessidades da nossa realidade. Um projeto que nós da escola e os professores de estágio da universidade criassem juntos. (...) Acho que isso é trabalhar em colaboração". (PE2, SIG4)
\end{abstract}

A fala da professora acima, a partir do significado que atribui ao TC,leva-nos a levantaras seguintes questões: por que os professores resistem ao trabalho em colaboração? Será que esses professores compreendem pouco sobre essa cultura de trabalho? Será que os professores não sabem e não se sentem confortáveis para trabalhar em parceria? A literatura consegue dar respostas as referidas perguntas. Segundo Fullan eHargreaves "a simples existência de colaboração não deve ser confundida com a consumação de uma cultura de colaboração" (2000, p.71).

Conforme citado pela fala da professora acima, trabalhar em colaboração pressupõe o desenvolvimento de projetos com objetivos muito claros a serem alcançados. Com efeito,a parceria dos professores formadores, em um momento pontual,para viabilizar o ingresso de um professor estagiário na escola, não pode ser configurado como um trabalho colaborativo, mas sim como uma interação assente na cultura da colegialidade artificial, que são orientadas para a implementação, ou seja, os docentes são obrigados ou "persuadidos" a trabalhar em conjunto, tendo em vista implementar ordens de outros mais diretamente. (Hargreaves, 2001).

A partir do pensamento defendido pelo autor, faz-se necessário pontuarmos que esse momento de colegialidade pode representar uma "ponte" para a construção de uma cultura de colaboração autêntica futura entre os professores. Nesse sentido, tanto a colegialidade artificial quanto a colaboração são "consideradas como pontes vitais entre o desenvolvimento das escolas e dos professores" (HARGREAVES,2001, p.209).

Assim, como revela a fala anterior da professora (PE2, SIG4), outra professora nos chama a atenção quanto a frequência com que o TC ocorre entre os professores da universidade e os da escola. Ela expressa: "Eu penso que o TC pode ser visto sob duas perspectivas. Em um momento pontual - o estágio - e, em um período mais longo, sendo entendido como uma prática permanente." (PU1, SIG2)

Os fragmentos anteriores tecem uma crítica à forma de trabalho dos professores formadores, no que tange ao TC. Para eles, se faz necessário que o TC faça parte da sua rotina de trabalho, não acontecendo apenas num momento pontual que é o estágio pedagógico. As falas revelam que o momento do cumprimento da disciplina estágio curricular supervisionado, é o momento que convida, impõe a esses professores o trabalho em parceria. A partir dessa perspectiva, questionamos 
os motivos que levam esses professores a não fazerem da colaboração uma prática rotineira na sua cultura de trabalho. A fala da professora formadora, a seguir ajuda-nos a responder a essa questão."Mas é preciso construir essa cultura de trabalhar com o outro, de socializar impressões, experiências, críticas, visando o aprendizado e a renovação do saber-fazer". (PU3, SIG8)

Esse posicionamento revela a pouca familiaridade que os professores têm com esse modo de trabalho em parceria, que entendemos como reflexo da ausência de uma formação docente orientadapara o trabalho em colaboração. Essa ausência é justificada pela prevalência de uma cultura individualista e privatista de trabalho que ainda faz parte do habitus profissional dos professores. Diante desse contexto, Damiani (2008, p. 219) pontua que "ao longo da história, os professores vêm trabalhando individualmente e essa tendência parece não ter mudado".

Assim, compreendemos que um desafio dos cursos de formação de professores é o de minimizar a influênciadessa cultura solitária de trabalhar e propor uma formação docente, sob a perspectiva da colaboração. Deste modo, podemos vislumbrar possíveis mudanças da ação docente e construirmos essa cultura de trabalhar com o outro, conforme citada pela fala da professora (PU3, SIG8).

Pensamos, assim, dar a devida atenção ao que defende Roldão(2000), quanto aos critérios que devem balizara formação docente. A referida autora argumenta que se faz necessário "formar para compreender e analisar situações de ensino; formar para decidir; formar para uma cultura profissional colaborativa; formar para avaliar a acção; formar para saber descrever, investigar e questionar as práticas" (p.19-20). Dentre todos os critérios defendidos pela autora, salientamos que esta perspectiva de formar para uma cultura profissional colaborativa deixa clara a ideia de que o TC pode evitar o isolamento, que é uma das características da profissão docente, tanto no campo da formação quanto do ensino.

Logo, o diferencial que essa formação docente, orientada para a colaboração poderá trazer aos sujeitos envolvidos, é conferir sentido às relações estabelecidas com seus colegas, a partir da partilha de experiências, saberes e construção de novos conhecimentos, com vista a operacionalização de mudanças significativas nas práticas pedagógicas em sala de aula e, consequentemente, o desenvolvimento profissional desses professores, tal como se discutirá a seguir.

\section{b) As mais-valias do trabalho colaborativo}

Aprendizagem, resolução de problemas, inovação e transformação da prática docente, desenvolvimento profissional. Essas são umas das palavras que descrevem bem as maisvalias que o TC apresentaaos professores que acolhem essa cultura de trabalho. A aprendizagem e a resolução de problemasforamcitadas por três das seis professoras entrevistadas, como umas das contribuições do TC. Vejamos as seguintes falas:"Aprende-se uns com os outros" (PU1, MV2).“Teríamos os nossos problemas resolvidos ou lidaríamos com eles de uma forma mais leve" (PE1, MV1) "Acredito que assim aprende-se mais..." (PU2, MV4)." nos faz sentir mais poderosos, mais proativos para tratarmos dos nossos problemas, para realizarmos os nossos projetos" (PU1, MV3).

Os posicionamentos acima nos revelam que os professores percebem o porquê de estarmos abertos à presença da colaboração, nas nossas práticas cotidianas de trabalho, e investirmos mais em projetos de colaboração. A partir dessa perspectiva, Alarcão (2010) defende que a colaboração aponta uma orientação, identifica uma finalidade maior, uma razão de estar em colaboração com os seus pares e deixa entrever mais-valias.

Outra mais-valia do trabalho em parceria, pontuada pelos inquiridos é a possibilidade de se oferecer uma melhor formação aos futuros professores. Uma formação docente que estejamais alinhada às necessidades reais desses alunos do contexto público de ensino. Prestemos muita atenção às falas que se seguem:

"E quando a gente consegue fazer essa parceria a gente consegue entrar no mundo do aluno (...) então esse professor regente (escola), nessa parceria colaborativa com o professor formador (da universidade) (...) ela consegue passar um pouco essa realidade do aluno para que o ensino possa ser planejado, a partir desse mundo do aluno e desse mundo da escola real (...)" (PU2, MV6).

Depreende-se dessa fala, que a professora faz uma crítica a formação que se pratica nos cursos de formação docente, formação esta, distanciada do terreno da prática e que o TC representa uma cultura de trabalho que gera, promove essa necessária relação dialógica entre os saberes da academia e os saberes da escola. A referida fala revela essa lacuna existente entre essas duas instituições formadoras e que os professores desejam e apostam na implementação da cultura do TC para 
que essa lacuna formativa seja minimizada ou desconstruída. As narrativas das professoras a seguir ratificam essa ideia:"E acho que teríamos um resultado melhor nas nossas atividades (...) e na formação dos alunos que estão aprendendo a ser professor, se tivéssemos essa forma de trabalhar" (PE3, MV5).“Acredito que assim (...)forma-se melhor" (PU1, MV4).

Assim, compreendemos que essa parceria entre os professores formadores se faz necessária para que possamos elucidar o valor dos contributos, tanto dos professores da universidade quanto dos professores da escola, que constituem culturas de trabalho e produção de saberes distintos. Pensamos, a partir do exposto, que se torna urgente para os professores formadores romper com esse hiato colaborativo nos campos da formação, investigação e ensino (Zeichner,1998). Corroborando com a ideia do referido autor, Nóvoa (1992) afirma que o diálogo compartilhado entre os formadores é imprescindível para alicerçar saberes emergentes da prática profissional, pois as redes coletivas de trabalhos constituem um fator decisivo para a construção e ressignificação de valores próprios da profissão docente.

Outro elemento pontuado por um dos professores entrevistados no tocante as mais-valias do TC é o desenvolvimento do espírito de equipe, no seio desta cultura de trabalho, o qual se confirma ao dizer que:"Os contributos são inúmeros, mas o mais importante deles é esse espírito de time/equipe que nos faz sentir mais poderosos." (PU1, MV3).

Percebemos que a fala da professora acima revela um sentimento de empoderamento que o TC proporciona. Entendemos que o "estar junto" nos leva a um conforto necessário para inovarmos, arriscarmos, abraçarmos novos projetos, testarmos novas possibilidades, sempre com um objetivo comum - permitir e promover novos processos de desenvolvimento profissional. Nessa direção, Delgado, Brocardo e Oliveira (2014, p.87) afirmam que "o trabalho em equipe poderá trazer um possível acréscimo de segurança em mudar ou inovar, ao possibilitar a partilha de diferentes experiências, perspectivas e modos de atuar".

Outra mais-valia que também foi revelada, pelas vozes dos inquiridos, foi o desenvolvimento profissional dos sujeitos envolvidos nessa dinâmica de trabalho em parceria. Nessa direção, Alarcão e Canha(2013) entendem o desenvolvimento profissional como um processo sistemático de aprofundamento e reconstrução do conhecimento com o objetivo precípuo de aperfeiçoamento da prática. Os autores ainda evidenciam que "é um processo que acompanha a vida e é potenciado através de experiências colaborativas de aprendizagem e de formação" (Alarcão e Canha 2013, p. 52). Mas, no caso específico deste estudo, daremos especial atenção ao desenvolvimento profissional dos professores formadores, neste momento de vivência da unidade curricular estágio pedagógico, embora concordemos com o posicionamento dos autores. Vejamos o que revelam as falas das professoras:"Todos cresceriam com essa experiência" (PE1, MV7)."Podemos nos desenvolver muito como profissionais, sob essa perspectiva da colaboração" (PE3, MV8).“os contributos seriam muito significativos, pois contemplariam o desenvolvimento profissional de todos os envolvidos" (PU1, MV9).
As falas acima não revelam, de forma clara, o significado que os professores atribuem ao desenvolvimento profissional. Não sabemos se eles se referem ao desenvolvimento de habilidades e competências para o exercício da profissão docente, a construção de saberes mais práticos da docência, a aquisição de conhecimentos didáticospedagógicos, ao desenvolvimento de uma atitude reflexiva sobre a prática, ao desenvolvimento de competências básicas de ensino. Os dados analisados não evidenciam a percepção que as professores formadoras têm sobre desenvolvimento profissional. O que nos revelam as falas é que elas são unânimes em reconhecerem que os contributos são significativos. Conforme citado pela professora a seguir:

"E acho que teríamos um resultado melhor... na formação de nós mesmos ... se tivéssemos essa forma de trabalhar" (PE3, MV5).

Assim, conforme a fala acima, compreendemos quea cultura de trabalho colaborativo poderá ressignificar o processo de formação dos professores, pois rompe com o padrão de trabalho isolado, otimizando a aprendizagem, o desenvolvimento profissional, a partir dessa parceria entre formadores da universidade e da escola. O sucesso do desenvolvimento profissional depende muito mais do contexto em que ele ocorre, do que das estratégias que são utilizadas para promovê-lo. A natureza desse contexto pode determinar ou travar o desenvolvimento do professor (HARGREAVES; FULLAN,1992).

\section{c) Dificuldades para implementação} do TC 
Relativamente às dificuldades para a implementação e vivência do TC, no âmbito da disciplina estágio curricular supervisionado, as professoras formadoras entrevistadas revelaram uma falta de formação para realizar esse trabalho em parceria e, igualmente, a ausência de espírito aberto dos seus intervenientespara a transição de uma cultura de isolamento para uma cultura de parceria.Tais posicionamentos expressam-se nas falas das professoras abaixo:"acho que não sabemos trabalhar assim. Não estamos acostumados. Não fomos formados para isso, para a parceria. Para alguns, trabalhar junto é muito mais complicado" (PE1, DIF1).

Para além da prevalência da cultura do isolamento docente, como elemento que dificulta o desenvolvimento do trabalho em colaboração, que já foi discutido neste artigo, outro aspectoque apresenta dificuldades para a implementação do TC é, segundo Hargreaves(1998), a insuficiente preparação dos professores para trabalhar em parceria, conforme citado pela fala da professora (PE1) acima. Assim, pensamos que se torna urgente uma mudança de lógica de formação docente, assente nos contextos de trabalho e nas experiências dos sujeitos, práticas formativas estas que devem se articular com as situações de trabalho e os quotidianos profissionais, organizacionais, numa perspectiva de formação em contexto (FERREIRA,2009).

Também é possível perceber, nas falas de duas professoras formadoras, que o excesso de tarefas que os professores têm de administrar, em suas rotinas de trabalho, representa outro obstáculo para a implementação do TC. Afirmam elas:"Mas os professores têm tantas tarefas para dar conta que não há tempo para trabalhar na colaboração" (PE1, DIF1)."Muitas horas de trabalho em sala de aula, muitas escolas para dar aula, muitas reuniões. Muitas tarefas dos dois lados! Como haver colaboração assim? É difícil!" (PU3, DIF3).

Com efeito, conforme as narrativas acima, não podemos deixar de chamar atenção para a sobrecarga de trabalho a que os professores estão submetidos e tantas outras responsabilidades que os mesmos têm de lidar, em suas atividades profissionais. Desse modo, não devemos "culpá-los", exclusivamente, pela ausência de uma cultura colaborativa em seu habitus profissional.É de se destacar ainda que a dificuldade para implementação dessa cultura não advém apenas da má vontade dos professores (ROLDÃO,2007).

$\begin{array}{lccr}\text { Seguindo a mesma linha de } & \text { autora }\end{array}$ supracitada,Mesquita, Formosinho e Machado (2015) salientam que "temos de analisar em paralelo a questão das condições organizacionais (horários compartimentados, cumprimento do currículo, etc.) e estruturais (a organização por departamentos, limitações entre os campos de conhecimentos, etc.) onde esses professores desenvolvem seu trabalho" (2015, p.48-49).

Diante desses reflexos, não só compete às instituições formadoras redefinirem os princípios formativos que irão orientar a preparação desses futuros professores para o ofício da docência, mas, igualmente, essas mesmas instituições e as escolas precisam construir uma nova lógica estrutural e organizacional com vista a viabilizar a implementação de comunidades de trabalho colaborativo.

\section{Considerações finais}

Durante o processo de construção deste trabalho, ao realizar inúmeras leituras para delinear o aporte teórico que balizou este estudo, nos foi possível perceber o lugar de importância conferido ao trabalhocolaborativo parapromover o empoderamento dos professores e, a partir desse empoderamento, possíveis inovações no seu fazer pedagógico e nos contextos de trabalho, particularmente, no âmbito do estágio pedagógico.

A proposta deste artigo foi identificar os contributos que o TC poderá oferecer, na experiência de estágio pedagógico, ao desenvolvimento profissional dos professores formadores. De modo a dar resposta a questão que norteou este estudo, escutamos as vozes do terreno de formação, a partir da realização de entrevistas a professoras formadoras da universidade e das escolas.

As vozes revelaram que a colaboração entre as professoras formadoras, durante as atividades de estágio, não é considerada como uma atividade permanente. Os dados registraram que é uma atividade que ocorre em um momento pontual, o momento de preparação do professor estagiário para ingressar na escola para a experiência do estágio pedagógico e, na perspectiva dos inquiridos, essa atividade não apresenta um cariz genuinamente colaborativo.

Sob essa perspectiva, algumas professoras perceberam o trabalho colaborativo, a partir do cumprimento de algumas atividades de ajuda, suporte, apoio e aconselhamento entre os colegas para o cumprimento de suas rotinas de trabalho.Em contrapartida, alguns dados também expõem que estas atividades não configuravam TC. 
Face ao exposto, Day (2001) destaca que culturas de colaboração dessa natureza são denominadas "colaboração confortável"que se preocupa, primariamente, com as questões imediatas, práticas e a curto prazo, excluindo uma pesquisa sistemática e crítica das questões que emergem da prática docente.

Para alguns professores, as falas revelaram que para que haja a cultura de colaboração autêntica, a existência de metas definidas pelos docentes, a partir da elaboração de projetos, entre os professores da universidade e os professores da escola, para uma melhor formação do professor estagiário, é condição precípua para a colaboração ser autêntica. Partindo dessa premissa, Araújo e Sá (1999) defende que enquanto as instituições formadoras não forem capazes de articular os seus percursos em projetos de desenvolvimentos partilhados, significativos, apoiados num conhecimento e respeito mútuo e profundo as questões que as mesmas enfrentam só encontrarão soluções pontuais, ocasionais e assistemáticas.

As falas das professoras entrevistadas também nos ajudaram a perceber que, a partir dessa colaboração entre os pares, desenvolveu-se um sentimento de eficácia, relativamente a realização das atividades docentes e resolução de problemas. Ficou evidente que os professores, ao estabelecerem parcerias para melhor lidar com as demandas de suas práticas, conseguem abrir espaço para a construção do trabalho, sob a égide da colaboração, minimizando, assim, a cultura do isolamento que ainda se faz presente em suas realidades de trabalho.Nesse sentido, Day (2004) ressalta que a cultura de colaboração minimiza o sentimento de impotência dos professores e aumenta a sua autoeficácia coletiva e individual.

A análise dos dados, permitenos também concluir que,de todos os elementos citados como entraves para a implementação do TC, nomeadamente, a falta de formação dos professores para trabalharem colaborativamente, sobrecarga de trabalho, prevalência da cultura do isolamento em seu habitus profissional, nenhuma dessas dificuldades podem ser retiradas do caminho das instituições que pretendam desenvolver essa cultura de trabalho, se não houver espaços que ofereçam mais oportunidades para que a interação entre os professores formadores aconteça, quando os mesmos desejarem investir neste tipo de relacionamento profissional (Lima, 2002).

Por tudo isto que a análise dos dados evidenciou, sobre os contributos que o TC poderá oferecer, na experiência de estágio pedagógico, para o desenvolvimento profissional dos atores educativos envolvidos nesse processo, permite-nos concluir que apesar de as professoras entrevistadas terem reconhecido as mais-valias da colaboração, e desejarem experienciar essa cultura de trabalho, muitos são os desafios para que o TC seja implementado e sustentado. Diante disso, se faz necessário um investimento constante nos estudos sobre a colaboração entre professores, para uma sensibilização e conscientização desses profissionais, quanto ao valor do TC para a renovação dos saberes da prática e da formação e, consequentemente, para o desenvolvimento profissional dos professores em exercício e daqueles em formação - os professores estagiários.
Referências

ALARCÃO, I. Formação reflexiva de professores - estratégias de supervisão. Porto: PortoEditora, 1996.

ALARCÃO, I. Professores reflexivos em uma escola reflexiva. 7. ed. Coleção Questões da nossa época. São Paulo: Cortez Editora, 2010.

ALARCÃO, I.; CANHA, B. Supervisão e Colaboração: Uma relação para o desenvolvimento. Coleção Nova CidineCinco, Porto: Porto Editora, 2013.

AMADO, J.; Ferreira, S. A entrevista na investigação em educação. In: AMADO, J. (Org.), Manual de Investigação Qualitativa em Educação. 2. ed., Coimbra: Imprensa da Universidade de Coimbra, 2014, p. 207-290.

ARAÚJO E SÁ, M. H. Investigação, formação e ensino: elementos para umadefinição de espaços de diálogos possíveis. In: VIEIRA, F., BRANCO, G.,MARQUES, I.,SILVA, J., MOREIRA, M. A.;SILVA E SILVA M.(Orgs.), Educação em Línguas Estrangeiras -investigação, formação e ensino. Actas do $1^{\circ}$ Encontro Nacional

Didática/Metodologiado ensino de línguas Estrangeiras. Minho: Universidade do Minho. 1999, p. 509522.

CANÁRIO, R. A prática profissional na formação de professores. In: CAMPOS, B. P. (Org.), Formação profissional de professores no ensino superior. Porto: Porto Editora, 2001, p.20-30. 
COSME, A.; TRINDADE, R. Manual de Sobrevivência para Professores.

Porto: Edições Asa, 2002.

DAMIANI, M. F. Entendendo o trabalho colaborativo em educação e revelando seus benefícios. Educar, v. 31,p. 213-230, 2008.Disponível em: ojs.c.3.sl.ufpr.br/ojs/index.php/educar/ article/view/12795. Acesso em 3 jan. 2015.

DAY, C. A Paixão pelo Ensino. Porto: Porto Editora, 2004.

\section{DAY, C. Desenvolvimento}

Profissional de Professores: os desafios da aprendizagem permanente. Porto: Porto Editora, 2001.

DELGADO, C., BROCARDO, J.; OLIVEIRA, H. Investigar as Práticas do Professor num contexto de trabalho colaborativo: potencialidades e desafios. Mediações Revista on-line da Escola Superior de Educação do Instituto Politécnico de Setúbal,2. ed. v.. 3, p. 87-97, 2014.Disponível em: http://mediações.ese.ips.pt Acesso em: 12 de dez. 2016.

DUBAR, C. Formação, trabalho e identidades profissionais. In: CANÁrio, R. (Org.), Formação e Situações de Trabalho. 2.ed. Porto: Porto Editora, 2003, p. 43-52.

FELÍCIO, H. M. S.; OLIVEIRA, R. A. A Formação Prática de Professores no Estágio Curricular. Educar Revista, v.32, 2008. p. 215-238.

FERREIRA, I. A Formação e seus efeitos. Do modelo escolar à formação em contexto. In: FORMOSINHO,J. (Coord.), Formação de professores. Aprendizagem profissional e ação docente. Porto: Porto Editora, 2009. p. 329-344.

FORTE, A.; FLORES, M. A. Concepções e práticas de colaboração docente. In: FLORES, M. A.;ALVES, M. P. (Orgs), Trabalho docente, formação e avaliação: clarificar conceitos, fundamentarpráticas. Mangualde: Pedago, 2010, p. 83-100.

FULLAN, M.; HARGREAVES, A. A Escola como organização prendente: buscando uma educação de qualidade. 2 ed. Porto Alegre: Editora Artes Médicas, 2000.

FULLAN, M.;HARGREAVES, A.

Por que é que vale a pena lutar? $O$ trabalho deequipa na escola. Coleção Currículo, Políticas e Práticas. Porto: Porto Editora, 2001.

GÓMEZ, A.;I. Pérez. (2001). Ensino para a Compreensão. In:

SACRISTÁN,J. G. S, GÓMEZ, A.;I. Pérez (Orgs.), Compreender e

Transformar o Ensino. 4.ed. Porto Alegre: Artmed Editora, 2001, p.6798.

HARGRAEVES, A. O Ensino como Profissão Paradoxal. Revista Pátio, IVed. v.16,p. 13-18, 2001.Disponível em:www.scielo.br/scielo.php?script=s ci_nlinks\&ref=000190\&pid=s0104.

Acesso em: 4 jan. 2014.

HARGREAVES, A. Os professores em tempos de mudança: o trabalho e a cultura dos professores na idade pósmoderna. Lisboa: McGraw- Hill, 1998.

HARGREAVES, A.; FULLAN, M. Understanding Teacher Development. New York: TeachersCollegePress, 1992.
IMBERÓN, F. Formação Docente e Profissional: formar-se para a Mudança e a Incerteza. 9. ed. Coleção Questões da Nossa Época. São Paulo: Cortez Editora, 2011.

LAGO, A. C. C.; OLIVEIRA, L. C., AVELINO, Y.C. O Trabalho Colaborativo na Formação de Professores: O AVA como espaço de mediação e práxis.Atas do VI ColóquioInternacional de Educação e Contemporaneidade.p. 20-22, 2012. São Cristóvão - Sergipe. Disponível em:educonse.com.br/2012/eixo_08/PD F/23.pdf. Acesso em: 22 de mar, 2014.

LIMA, J. As culturas colaborativas nas escolas: Estruturas, processos e conteúdo. Porto: Porto Editora, 2002.

LIMA, M.S.L. A Hora da Prática: reflexões sobre o estágio supervisionado e ação docente. 2. ed. Fortaleza: Edições Demócrito Rocha, 2001.

LIMA, M. S. L ; PIMENTA, S. G. Estágio e Docência. Coleção Docência e Formação. 4. ed. São Paulo: Cortez Editora, 2009.

LORTIE, D. C. Schoolteacher: a sociologicalstudy. Chicago, The University ofChicago Press, 1975.

MESQUITA, E.; FORMOSINHO, J.; \& MACHADO, J. Individualismo e colaboração dosprofessores em situação de formação. In:FORMOSINHO, J. F;MACHADO, J.;MESQUITA, E. (Orgs.), Formação, Trabalho e Aprendizagem Tradição e Inovação nas Práticas Docentes. Lisboa: Edições Silabo, 2015, p. 43-55. 
NÓVOA, A. Os Professores em

Formação. Lisboa: Dom Quixote, 1992.

OLIVEIRA, E.S. G.; CUNHA, V. L. O Estágio Supervisionado na Formação Continuada Docente à Distância: Desafios a vencer e construção de novas subjetividades.

Revista de Educação à Distância RED, v.14, 2014. Disponível em: http://www.um.es/ead/red/14. Acesso em: 18 jun. 2016.

PIMENTA, S. G. Formação de Professores: identidade e saberes da docência. In:PIMENTA, S. G. (Org.), Saberes Pedagógicos e Atividade Docente. São Paulo:Cortez Editora, 1999, p. 15-34.

PINTO, C. L. L.; LEITE, C. Trabalho Colaborativo: um conceito polissêmico. Conjectura: Filosofia e educação,19 ed. v.3, 2014, p. 143-170. Disponível em: https://repositorioaberto.up.pt/handle/10216/76616. Acesso em: 18 jun. 2016.

RODRIGUES, A.; NOLASCO, I.; FIADEIRO, P. "Línguas - caminhos para o outro": exemplo de uma "boa prática" com limites. In: ANDRADE A. I. A.;PINHO, A. S. (Orgs.),

Línguas e Educação: práticas e percursos de trabalho colaborativo. Perspectivas a partir de um projeto.Aveiro: Departamento de Educação, Universidade de Aveiro, 2010, p. 25-42.

ROLDÃO, M. C. Colaborar é preciso. Questão de qualidade e eficácia no trabalho dos professores. Noesis, v.71, 2007, p. 24-29.

ROLDÃO, M. C. Formar

professores: Os desafios da profissionalidade e o currículo. Aveiro: CIFOP, Universidade de Aveiro, 2000.

SOUZA, M. J.; BAPTISTA, C. S.

Como fazer investigações, dissertações, teses e relatórios.

Lisboa: Pactor, 2011.

VIEIRA, F.Enhancing pedagogy for autonomy through learning communities: making our dream come true? Innovation in Language Learning and Teaching, 3 ed. v.3, 2009, p. 269282.

ZEICHNER, K. M. Para além da divisão entre professor-pesquisador e pesquisador acadêmico. In: GERALDI, C. M.,FIORENTINI, D.,\& PEREIRA, E. M. (Orgs.), Cartografia do trabalho docente: Professorpesquisador. Campinas: Mercado das Letras, 1998, p. 207-236. 